\title{
THE DETERMINATION OF THE STRESS INTENSITY FACTORS OF A STEEL PLATE WITH DIFFERENT THICKNESS USING FEM
}

\author{
YOUNIS KHALID KHDIR ${ }^{1}$ \\ Department of Technical Mechanical and Energy Engineering, Erbil Technical Engi- \\ neering College, Erbil Polytechnic University, Erbil, Iraq
}

(Accepted for Publication: December 8, 2020)

\begin{abstract}
This paper presents the finite element method for determining the stress intensity factors of steel plates with different thickness having an elliptical cut-out in the center and subjected to different stresses. The failure of the cracked parts affected by the stresses in the crack tip vicinity. The stress contribution can be determined by the stress intensity factor K. For this purpose, an initial crack can be simulated and modeled. Each of $K$ corresponds to a crack propagation method. In this study the ANSYS software is used for numerical modeling with several elements of solid type and nodes. a finer mesh is used around the crack tip for more accurate results. Then an error percentage can be determined by using ANSYS results. The present research is aimed to improve the formulation by including the effect of the crack-face closure on the stress intensity factors $K$.
\end{abstract}

KEYWORDS: Stress Intensity Factor; Contact Pressure; Crack Growth; Finite Element Analysis; Fracture Mechanic.

\section{INTRODUCTION}

$\mathbf{I}$ most mechanical structures, the fatigue crack growth is mostly related to the stress distribution near and around the crack tip. Most of the studies about fatigue problems were initially focused only on two dimensions and neglecting any mechanisms taking place through the thickness of the specimen, or the effects of thickness on the crack tip behavior. Therefore, it seems very interesting to investigate the issue from the thickness as well. A number of studies have shown the crack front in fatigue through different parameters considering three-dimensional view. Other authors showed analytical solutions of crack tip stress (Hello et al., 2012). (Folias and Wang, 1990) presented analytical solution for the three-dimensional stress field in a plate of an arbitrary thickness, $2 \mathrm{~h}$, and weakened by a cylindrical hole of radius. They showed that the stress concentration factor varies across the thickness and is sensitive to the value of the radius to thickness ratio.

Different analytical formulas for different types of holes with cracks in a plate were presented with interpreting the propagation of the cracks by (Berezhnitskii, 1967). Two methods were presented to estimate post yield solutions for symmetric cracks emanating from elliptic holes. The first method simulates the cracks and plastic zone while the second method is based on the Green's function. Both methods are used to determine the stress intensity (Chell and Vitek, 1979). Based on the Green's function by using the Muskhelishvili formulation with a series of approaches in the two-dimensional theory of elasticity, the stress-intensity factors, were obtained for a point loaded crack emanating from a circular hole in an infinite plate in biaxial tensile loads and bending cases (Shivakumar and Forman, 1980).

(Cheong and Hong, 1988) presented through 
modification of mapping-collocation method the calculation of the mixed-mode stress intensity factors of cracks emanating from a circular hole in an orthotropic infinite plate. Later for the three-dimensional stress field in a plate of an arbitrary thickness weakened by a cylindrical hole, an analytical solution, was presented by (Folias and Wang, 1990). Some authors modified the results for that of a circular hole in an infinite plate to estimate the stress intensity factors (SIFs) for two symmetric cracks at the edge of an elliptical hole in a finite and an infinite plate under a pair of point loadings (Lam et al., 1996). While others used a simple engineering method through using finite element analysis for estimating the SIF around a quarter elliptical cracks emanating from a notch (Peng et al., 2005). Numerical analysis to evaluate the (SIFs) of cracks, emanating from an elliptical hole in a finite or in an infinite plate under biaxial loads in two dimensions was presented using a boundary element method by (Yan, 2006). Then (Yan, 2007) used the displacement discontinuity method with crack-tip elements to estimate the SIF of a rectangular tensile plate with single edge crack. Muskhelishvili's complex variable method was used to evaluate the (SIFs) for laminated composite infinite plate subjected to different arbitrary loading containing a cracks emanating from circular hole, by (Sharma and Ukadgaonker, 2008, Nui et al., 1994).

A combination of finite element method and the concepts of linear fracture mechanics to study the fracture and crack growth of the materials was well explained by (Souiyah et al., 2008), using two dimensional elements to evaluate the (SIFs) for a crack emanating from circular hole of a plate under tensile loading. A numerical investigation of transition of specimen cracks in two dimensional was presented to evaluate the plastic zone and the thickness effects that influences on fracture mechanics by (Camas et al., 2011). Analytical formulation of SIF for a crack repaired with bonded composite patch in aircraft structure which it is emanating from central holes was studied by (Albedah et al., 2013), the authors developed Kujawski method for cracks emanating from notch without repair.

(Garcia-Manrique et al., 2013) calculated the stress intensity distribution along the thickness of $\mathrm{Al}$ 2024-T35 compact tension specimens at different planes under mode I nominal loading. Whereas (Tada et al., 2000, Schijve, 2001, Broek, 2012) presented three modes of crack propagations, each mode has a corresponding stress intensity factor (SIF), mode I KI opening, mode II KII sliding and mode III KIII tearing. These factors KI, KII, KII can be estimated either by using fracture mechanics formulas, where the loading conditions and the geometry of the crack should be considered; or through a finite element method FEM software. For the complex crack geometries, it is preferable to use FEM software. The Improved (SIFs) was determined by (Evans et al., 2014) for a large plate containing a single corner crack at a filled fastener hole under tensile load. (Liu and Duan, 2014b, Liu and Duan, 2014a) presented an analytical solution for (SIFs) under uniform tension and shear separately of two collinear edge cracks of unequal length emanating from an elliptic hole in an infinite plate.

The FASTRAN life-prediction code was used by (Newman Jr and Daniewicz, 2014) to estimate the crack growth in a specimen made on two aluminum alloys with overloads and cold-worked compressive residual stresses. (Han et al., 2015) showed three simples through thickness mode I fatigue cracks, displacements, stresses around crack tips can be determined by finite element analysis considering different types of elements. (Jing and Wu, 2015) presented a (SIFs) for arbitrarily shaped crack geometries in a wide-range weight functions using complex Taylor series expansion method Some authors studied the SIF of a crack initiation at elliptical holes in plates subjected to 
uniaxial tension using analytical finite fracture mechanics approach's close form (Weißgraeber et al., 2016). Studying the mechanical behavior of two asymmetrical limited permeable cracks emanating from an elliptical hole was explained for one-dimensional hexagonal quasicrystals with piezoelectric effect by (Yang et al., 2017) investigating by adopting the technique of conformal mapping and the Stroh-type formalism. Numerical procedure to simulate multiple three dimensional crack propagation in friction stir welded structure using finite element method was proposed by (Lepore et al., 2017), the authors studied the (SIFs) considering temperature dependent elastic-plastic material properties using a by a thermo-mechanical FEM simulation of the process.

A semi-analytical approach depend on complex potential theory in combination with a two-scale asymptotic analysis was proposed by (Felger et al., 2017) to evaluate the size of instantaneously initiating cracks and the effective strength of the notched plate. (Wu et al., 2018) presented a study of verification for two recently developed weight functions by (Jing and $\mathrm{Wu}, 2015)$ for two symmetric radial cracks or a single crack emanating from a circular hole in an infinite plate, and comparing it with Green's functions (Shivakumar and Forman, 1980). The observation of the fatigue damage evolution in the composite plate with multilayered including an elliptical hole in the middle was explained using the infrared thermography and lamb wave propagation method by (Stawiarski, 2018). A complex variable theory of Muskhelishvili was used by (Hajimohamadi and Ghajar, 2019) to study an infinite quasi orthotropic plane with a cracked circular hole subjected to tensile loading at infinity. (Şahin and Ayhan, 2019) presented three-dimensional (SIFs) for inclined elliptical surface cracks under uniform tensile load in plates in terms of normalized mixed mode (SIFs) along crack fronts. A practical SIF formula for a steel plates with a central crack based on thorough finite element analysis were investigated by (Liu et al., 2019).

Another study presented that the threshold SIF range can be obtained using the threshold SIF range decreasing method, based on the plasticity-induced crack closure model ( $\mathrm{Li}$ et al., 2019). The estimation of fatigue growth of a circular hole with emanating a corner crack was demonstrated and validated against test data by (Guo et al., 2020). A study about fracture on dissimilar metal plate with center crack made up of ferritic steel, austenitic steel and Inconel -182 alloy has been presented by (Vishnuvardhan, 2020) using two- and three-dimensional finite element analysis with center crack for various crack lengths and different dissimilar metal welded joint widths to estimate SIF. (Camas et al., 2020) presented a numerical modelling of three-dimensional fatigue crack based on finite element method to evaluate the plasticity induced crack closure occurrence for a long time.

The aim of this study is to present the study of crack tip fields which can be conducted by estimating the behavior through variable thickness values. In addition, the work in this paper presents the relationship between each of the SIF, the applied pressure and thickness of the specimen. The present paper is organized as follows; in Section 2, the investigated microstructure using finite element method, methodology and indicating boundary conditions is presented. Then, the proposed model using ANSYS finite element software is compared with theoretical solutions of (Newman, 1981, Newman Jr, 1983, Newman Jr and Daniewicz, 2014) and the results are presented and discussed in Section 3, Concluding remarks are finally given in Section 4 .. 


\section{COMPUTATIONAL DESCRIPTION AND MATHEMATICAL MODEL}

\subsection{Computational Description}

In this section the procedure of creating a three-dimensional microstructure through the use of finite element meshing for the tested plate is presented. With determining materials properties, which are required for the modeling and the numerical analysis by ANSYS 15 the boundary conditions is explained. The size of the mesh and the steps of the numerical calculation and mathematical model are explained in detail.

\subsection{Materials and approaches}

In this work a steel plate with a central elliptical cut-out is investigated. Figure 1. shows the simulation model of the plate with dimensions, which it is considered as an initial crack in the plate (Pilkey and Pilkey, 1994). The model is used for the determination of the (SIFs) for different thicknesses as explained in Figure 2. The properties of the material is structure is (steel) is $7850 \mathrm{~kg} / \mathrm{m}^{3}$ of density, coefficient of thermal expansion $1.2 \times 10^{-5}{ }^{\circ} \mathrm{C}^{-1}$, tensile strength is $250 \mathrm{MPa}$, ultimate tensile strength is $460 \mathrm{MPa}$, and the Young's Modulus is 200 $G P a$, and Poison ratio is 0.3 . The dimensions of the used specimen are in SI unites which are depicted in Figure 1.

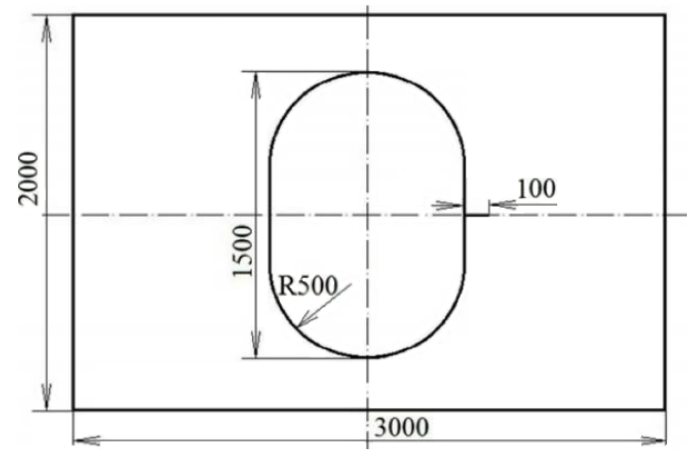

Fig. (1): The steel plate with the central elliptical cut-out and initial crack, dimensions in $\mathrm{mm}$.

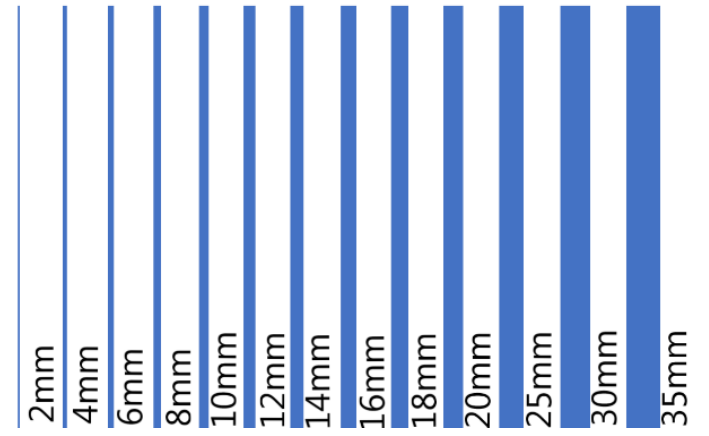

Fig. (2): Thicknesses of steel plates used in the finite element analysis, dimensions in $\mathrm{mm}$.

\subsection{Creating Microstructure}

There are a lot of schemes available to generate microstructures with different types of elements, The FE calculations were carried out using ANSYS 15 software package. The three-dimensional microstructure is created. The size of meshing should be fine enough so as the software produces an accurate result and noting that in the location of the crack the mesh size is finer, which the mesh type and more dense area of the mech are illustrated in Figure 3. The meshing size and the representative volume element are refined in the region of SIF in order to obtain more accurate results. The mesh type used in this research is free mesh because it can give more accurate results when compared with rectangular type. A tetrahedron mesh type which has 4 vertices, 6 edges, and is bounded by 4 triangular faces, and a three-dimensional element type are used. (Khdir et al., 2013, Khdir et al., 2014, Khdir et al., 2015). 


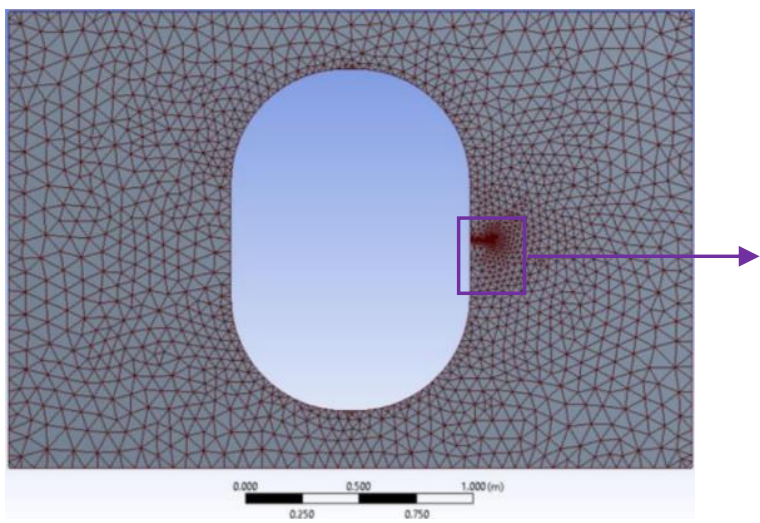

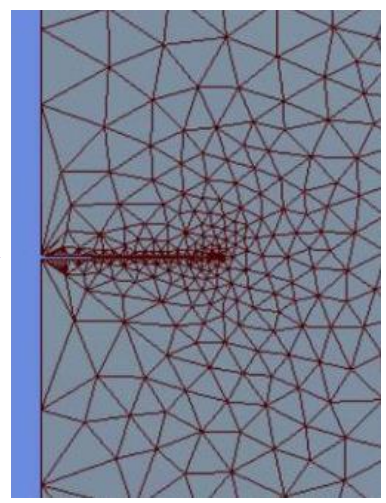

Figure 3. The steel plate with the tetrahedron mesh type (a), the finer mesh size around the crack (b).

\subsection{Boundary Conditions}

The second important step for the finite element tests, after creating the microstructures, concerns the boundary conditions. For the tensile loading in the $y$ direction, for example, Figure 4 prescribed these conditions as follows:

$$
\begin{array}{cc}
v\{\text { plane }(y=x, 0, z)\}=0 & u \text { point } B(l, 0,0)\}=0 \\
v\{\text { plane }(y=x, h, z)\}=\delta & u \text { point } O(0,0,0)\}=0 \\
w\{\text { point } A(l, 0, b)\}=0 & w \text { point } O(0,0,0)\}=0
\end{array}
$$

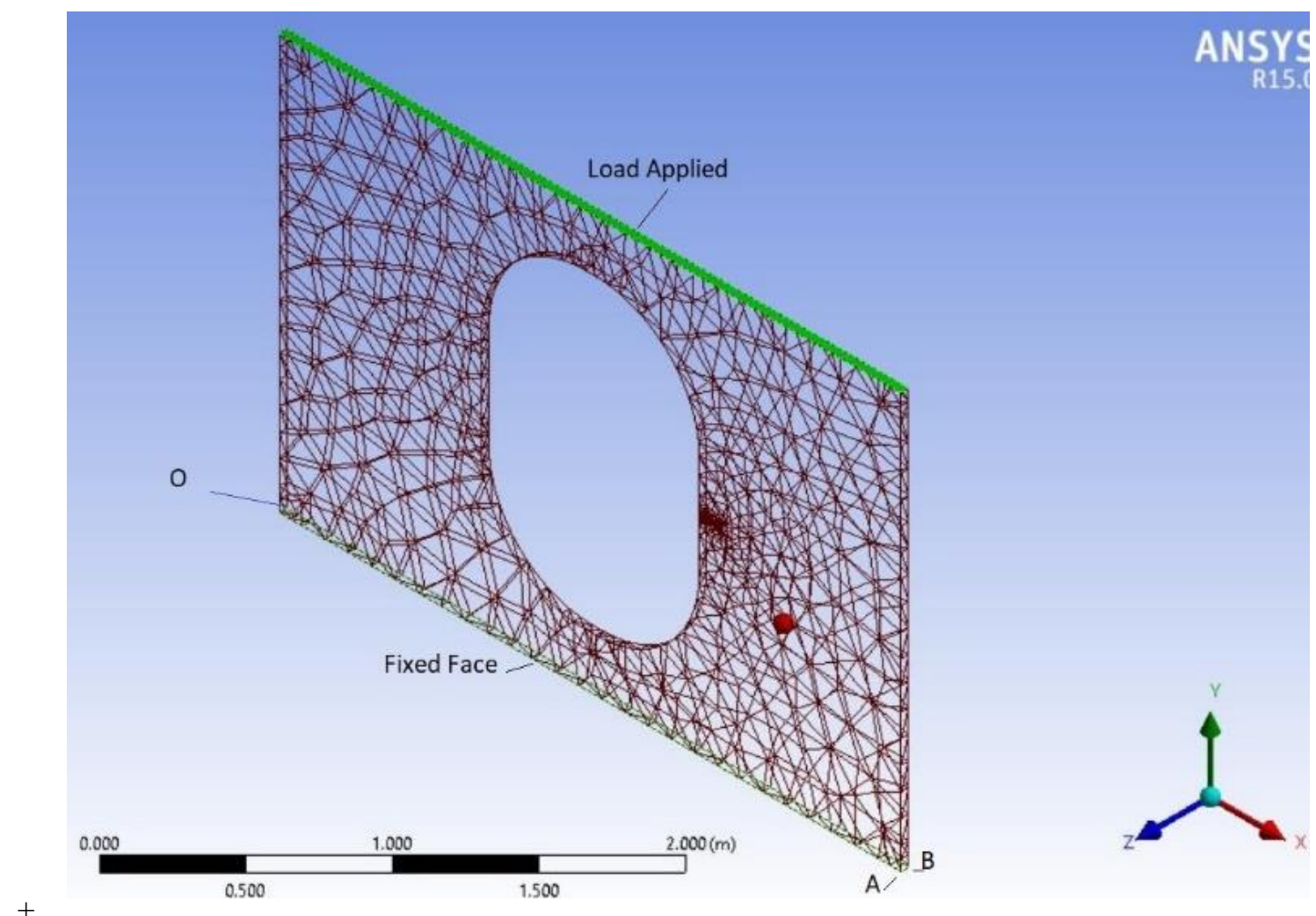

Fig. (4): The steel plate with applied boundary conditions. 
In which, $u, v$ and $w$ are the applied displacements in the $x, y$ and $z$ directions, $h, l$, and $b$ are the specimen's height, length and thickness respectively and $\delta$ is the prescribed displacement. On the bottom face the plate is fixed, so all degrees of freedom are zeros through points $A, B$ and $O$. The local coordinate system is applied for the crack, initially, on the top face a uniformly distributed tensile pressure is applied (Khdir, 2019).

\subsection{Finite Element Analysis}

The creation of the three-dimensional geometry of the plates and setting boundary conditions are the essential steps before any solution and then applying the solutions in
ANSYS, the minimum and maximum equivalent von Mises stresses can be determined as well as the (SIFs) modes I, II and III. Also, the stress distribution over the whole volume of the plate and the local stress intensity at each point can within crack vicinity be predicted

\subsection{Mathematical Models}

There are a lot of analytical models proposed by several authors as discussed in the introduction section. In this section three analytical model were selected to estimate the SIF. The first models depends on the analytical method proposed by (Murakami, 1987, Guo, 1999), to estimate the SIF $(K G M)$ for a compact tension specimen in mode-I as:

$$
K G M=\frac{P}{b \sqrt{w}}\left(\frac{2+\frac{a}{w}}{\left(1-\frac{a}{w}\right)^{\frac{3}{2}}} \cdot\left(0.886+4.64 \cdot\left(\frac{a}{w}\right)-13.32 \cdot\left(\frac{a}{w}\right)^{2}+14.72 \cdot\left(\frac{a}{w}\right)^{3}-5.6 \cdot\left(\frac{a}{w}\right)^{4}\right)\right)
$$

where $P$ is the load applied, $b$ is the specimen thickness, $w$ is the distance from the loading line to back face and $a$ is the crack length. The second model is based on the integral equation that proposed by (Berezhnitskii, 1967, Tada et al., 2000) to estimate the SIF of the plate for a crack emanating in an elliptical hole in a plate with the accuracy of $3 \%$, the SIF (KBT) can be determined as follows:

$$
K B T=P \sqrt{\pi a} \cdot F\left(s, \frac{c}{b}\right)
$$

$$
\text { for } s \rightarrow 0 \text { and }\left(\frac{a}{b}\right) \rightarrow 0: F\left(s, \frac{c}{b}\right) \rightarrow 1.122 . K_{t}
$$

where $s=\left(\frac{a}{b+a}\right), K_{t}=1+2\left(\frac{b}{c}\right)$

$$
\text { for } s \rightarrow 1 \text { and }\left(\frac{a}{b}\right) \rightarrow \infty: F\left(s, \frac{c}{b}\right) \rightarrow \frac{1}{\sqrt{2}}
$$

and for $c \rightarrow b, a: F\left(s, \frac{c}{b}\right) \rightarrow 1.122$

where $P$ is the load applied, $F$ is the shape factor, $c$ and $b$ are the minor and major radius of the elliptical hole respectively, and $a$ is the crack length.

The third model is based on the case study of (Newman Jr and Daniewicz, 2014) to estimate the SIF for a single crack emanating from an open hole in a finite width plate under uniform stress as:

$$
K N D=P \sqrt{\pi a} B_{c f}
$$

where $P$ is the applied stress, $a$ is the crack length measured from the hole, and $B_{c f}$ is the boundary-correction factor, which accounts for the finite-width and the influence of the hole. The function of $B_{c f}$ was well explained in (4) (Newman Jr, 1983) and can be determined by:

$$
B_{c f}=B_{n} B_{w}
$$

where

$B_{n}=0.707+0.765 \lambda+0.282 \lambda^{2}+0.74 \lambda^{3}+$ $0.872 \lambda^{4}$

where $\lambda=\frac{1}{1+a / r}$ for $0<\lambda \leq 1, r=$ radius of the hole, and

The finite width correction $B_{w}$ is equal to: 


$$
B_{w}=\sqrt{\frac{1}{\cos \left(\frac{\pi / 2(r+a / 2)}{\frac{l}{2}-a / 2}\right)}}
$$

Which agrees well with other solutions (Newman Jr and Daniewicz, 2014, Isida, 1966, Tada et al., 2000) where the width of the specimen is equal $l$ and the hole diameter is equal $2 r$. Before using the finite element software ANSYS R15.0, for each loading model, an analytical calculus was made. Considering the same pressure ratio applied on the cross-sectional area of the specimen.

\section{RESULTS AND DISCUSSION}

The plates with thirteen different thicknesses as indicated in Figure 2, and Table 1 have been simulated numerically using ANSYS R15.0 software, to estimate the stress intensity factor (K) for each model is based on the boundary conditions shown previously by equation 1 and Figure 4, with the dimensions which explained in Figure 1, and meshes shown in Figure 3. Different concentrations of the equivalent von Mises stresses are noticed based on the change of the thickness of the plate. As well showed in Figure $5 \mathrm{a}, \mathrm{b}$ and $\mathrm{c}$. the maximum and minimum equivalent von Mises stresses in each plate is different and varied according to the thickness of the plate as well as the distribution of the stresses is also changed. The von Mises stresses has not affected significantly affected by the thickness change, so this issue should be studied deeply in the future works.

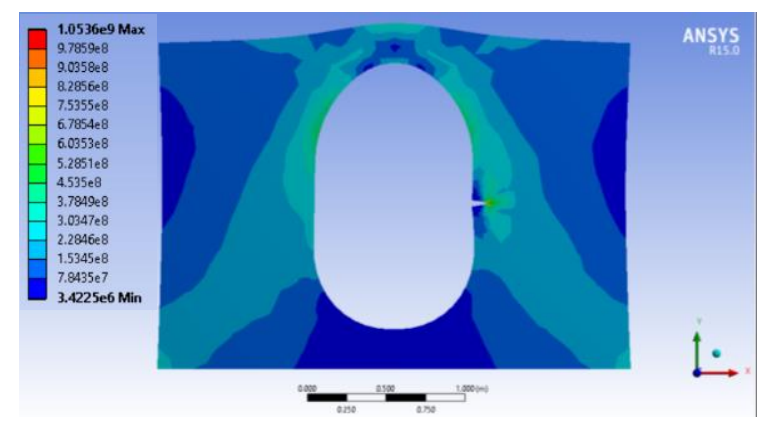

$\mathrm{a}: \mathrm{t}=2 \mathrm{~mm}$

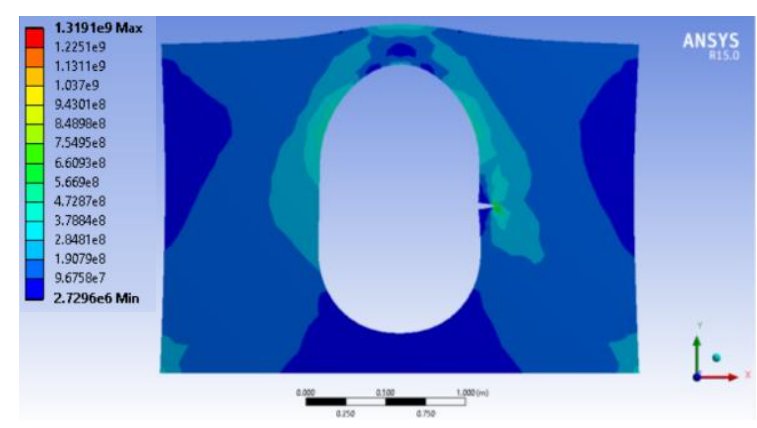

c: $\mathrm{t}=6 \mathrm{~mm}$

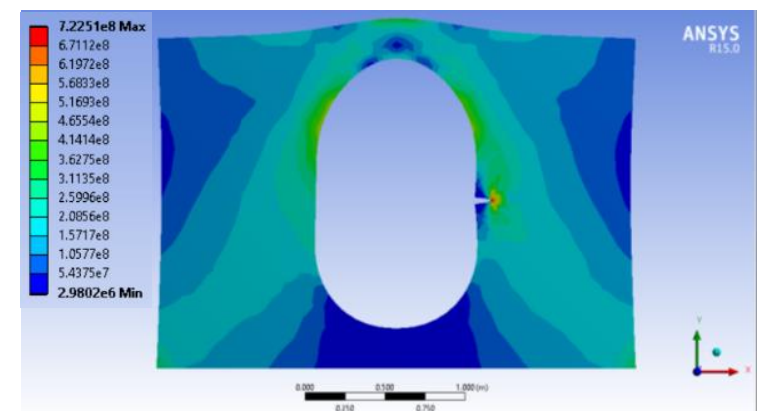

$\mathrm{b}: \mathrm{t}=4 \mathrm{~mm}$

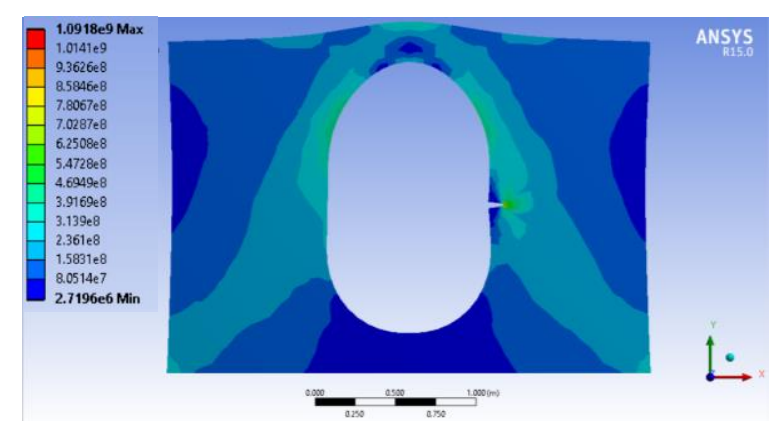

$\mathrm{d}: \mathrm{t}=8 \mathrm{~mm}$ 


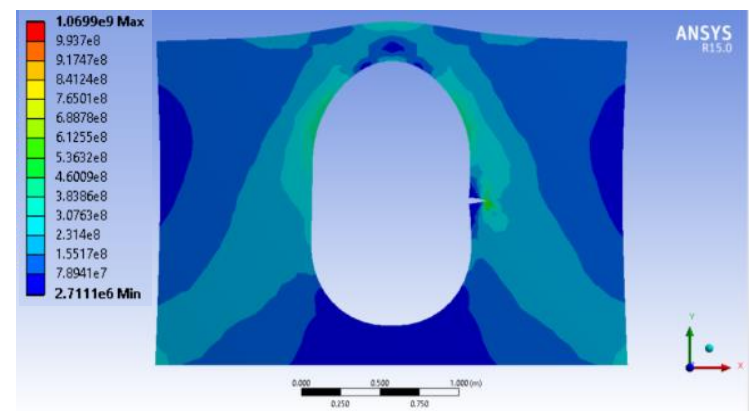

$\mathrm{e}: \mathrm{t}=10 \mathrm{~mm}$

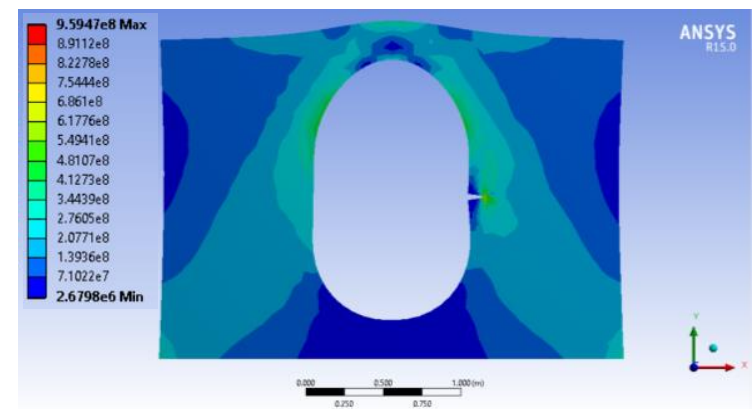

$f: t=12 m m$

Figure 5a Maximum and minimum von Mises equivalent stresses for the steel plate with different thicknesses, ANSYS results.

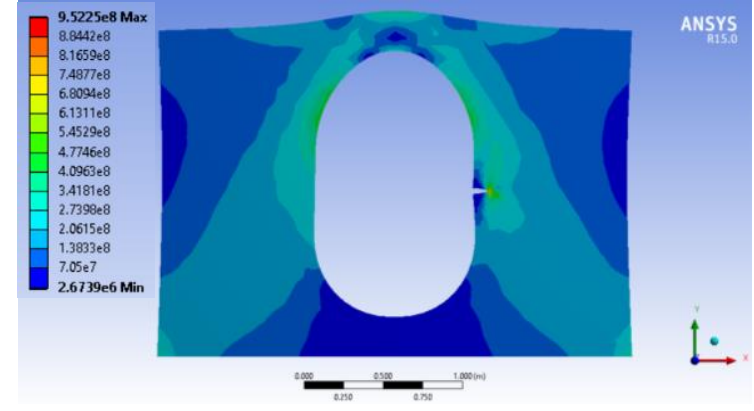

$\mathrm{g}: \mathrm{t}=14 \mathrm{~mm}$

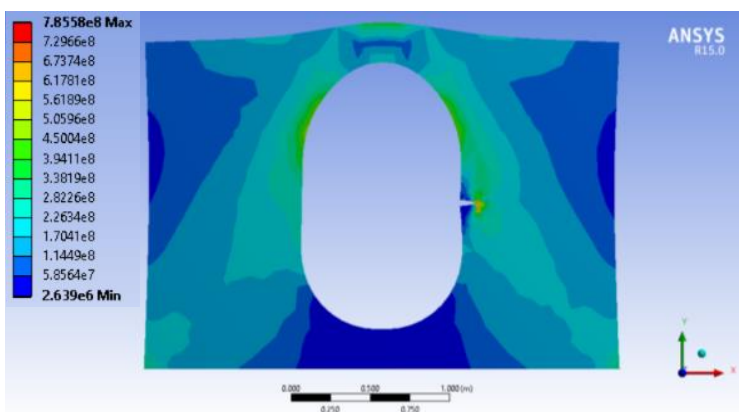

$\mathrm{i}: \mathrm{t}=18 \mathrm{~mm}$

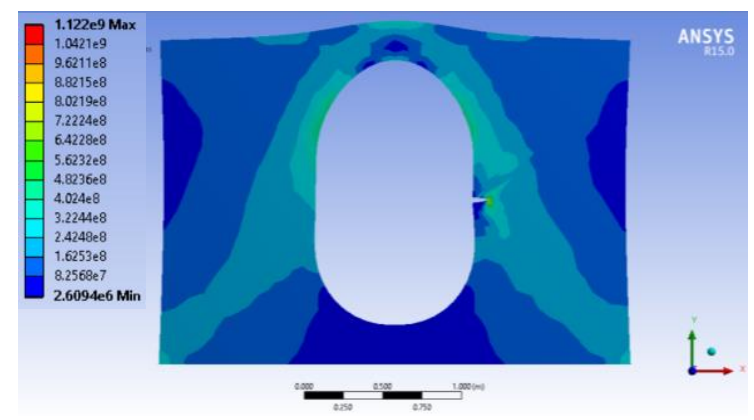

$\mathrm{k}: \mathrm{t}=25 \mathrm{~mm}$

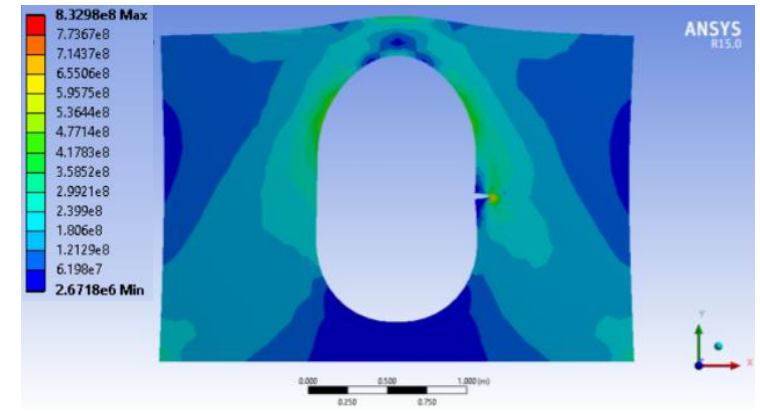

$h: t=16 m m$

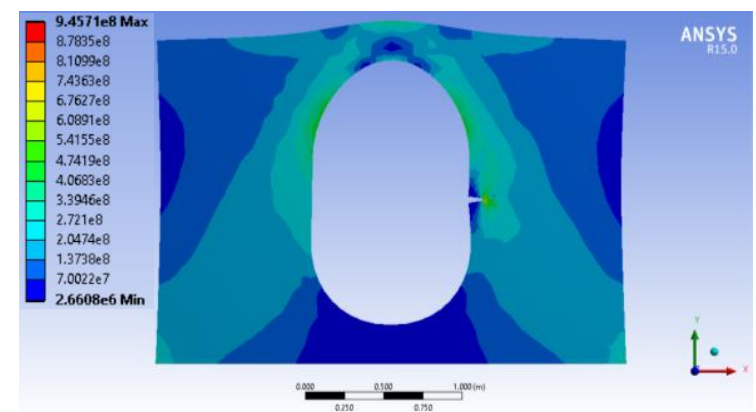

$\mathrm{j}: \mathrm{t}=20 \mathrm{~mm}$

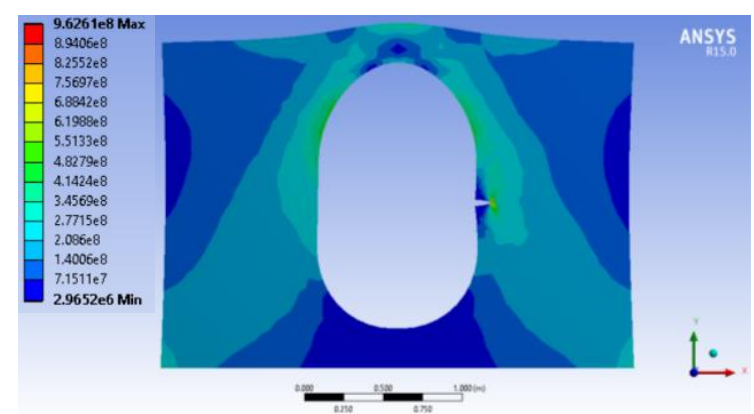

$\mathrm{I}: \mathrm{t}=30 \mathrm{~mm}$

Fig. (5b): Maximum and minimum von Mises equivalent stresses for the steel plate with different thicknesses,

ANSYS results. 


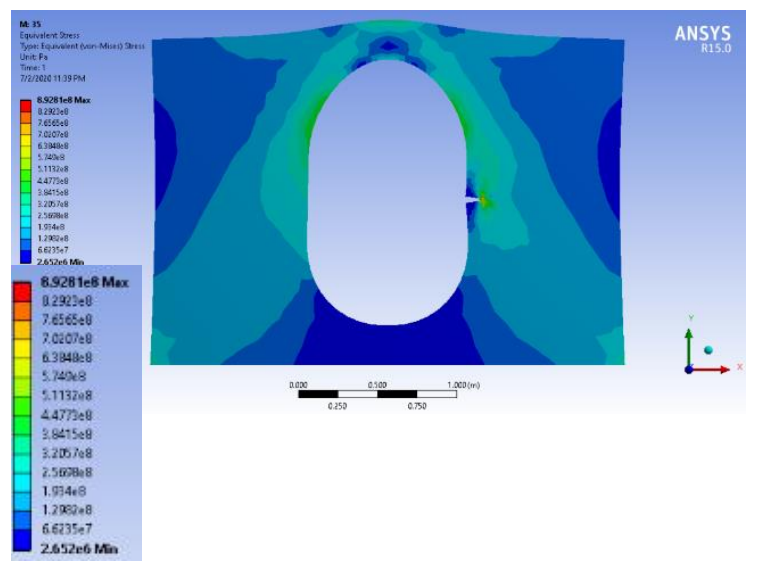

Fig. (5c): Maximum and minimum von Mises equivalent stresses for the steel plate with thicknesses $35 \mathrm{~mm}$,

ANSYS results.

It can be noticed that stress concentration occurs mostly near the location of the crack as indicated in Figure 6, of which, the maximum von Mises equivalent stress, the isolines of the same stress concentration and indicate the location of any weak points during the designing of plate.

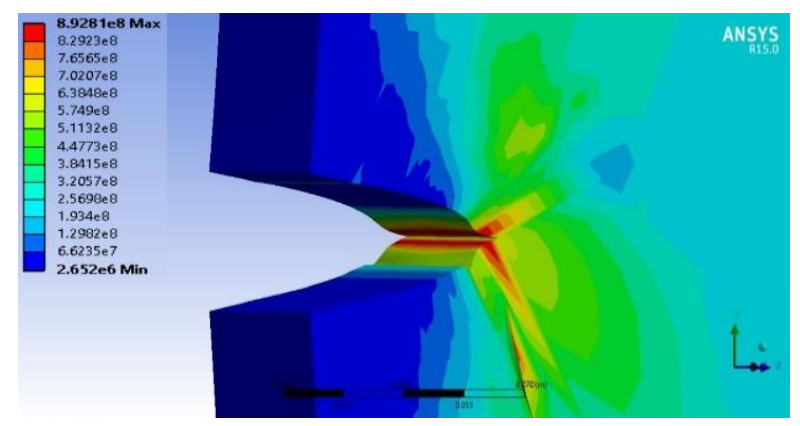

A

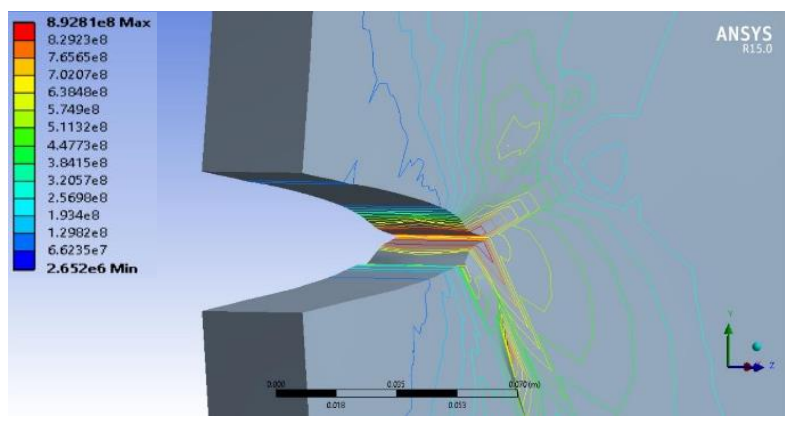

b

Fig. (6): The steel plate with $35 \mathrm{~mm}$ thicknesses used in the finite element analysis, the crack tip with aequivalent von Mises stress and b- the isoline stress distribution.

Table 1 shows all the results of the ANSYS software as the maximum and minimum von Mises stresses and the $\mathrm{K}$ for each tested plate thickness, noting that the same pressure ratio is kept during the tests.

Table (1): Maximum and Minimum von Mises stress and the stress intensity factors calculated by using the ANSYS software for the plate with a central cut-out and a crack

\begin{tabular}{cccc}
\hline $\begin{array}{c}\text { Plate } \\
\text { Thickness } \\
(\mathbf{m m})\end{array}$ & $\begin{array}{c}\text { Maximum } \\
\text { von Mises }\end{array}$ & $\begin{array}{c}\text { Minimum } \\
\text { von Mises }\end{array}$ & $\begin{array}{c}\text { Stress } \\
\text { Intensity }\end{array}$ \\
& $\begin{array}{c}\text { Stress } \\
(\mathbf{M P a})\end{array}$ & $\begin{array}{c}\text { Stress } \\
(\mathbf{M P a})\end{array}$ & $\begin{array}{c}\text { Factor } \\
\mathbf{M P a} \sqrt{\mathbf{m}}\end{array}$ \\
\hline 2 & 1053.6 & 3.4225 & 0.41078 \\
\hline
\end{tabular}




\begin{tabular}{cccc}
\hline 4 & 722.51 & 2.9802 & 0.8436 \\
\hline 6 & 1319.1 & 2.7296 & 1.1625 \\
\hline 8 & 1091.8 & 2.7196 & 1.7709 \\
\hline 10 & 1069.9 & 2.7111 & 1.7844 \\
\hline 12 & 959.47 & 2.6798 & 1.9838 \\
\hline 14 & 952.25 & 2.6739 & 2.3139 \\
\hline 16 & 832.98 & 2.6718 & 3.0958 \\
\hline 18 & 785.58 & 2.639 & 3.1958 \\
\hline 20 & 945.71 & 2.6608 & 3.3016 \\
\hline 25 & 1122 & 2.6094 & 4.1978 \\
\hline 30 & 962.61 & 2.9652 & 5.0015 \\
\hline 35 & 892.81 & 2.652 & 5.7828 \\
\hline & & & \\
\hline
\end{tabular}

\subsection{Relationship between maximum Von}

\section{Mises Stress and the thickness of the plate}

The relationship between the maximum von Mises stress and the thickness of the plate is shown in Figure 7. The stress intensity and the equivalent stress varies differently for plate thicknesses of 2, 12, 14, 16 and $18 \mathrm{~mm}$, the equivalent von Mises stress is found to be lower than those of other plates of 6 , and $24 \mathrm{~mm}$ thickness. The best von Mises result can be noticed with $4 \mathrm{~mm}$ plate thickness. Also, it can be observed that there is no significant relationship between the von Mises stress and the plate thickness.

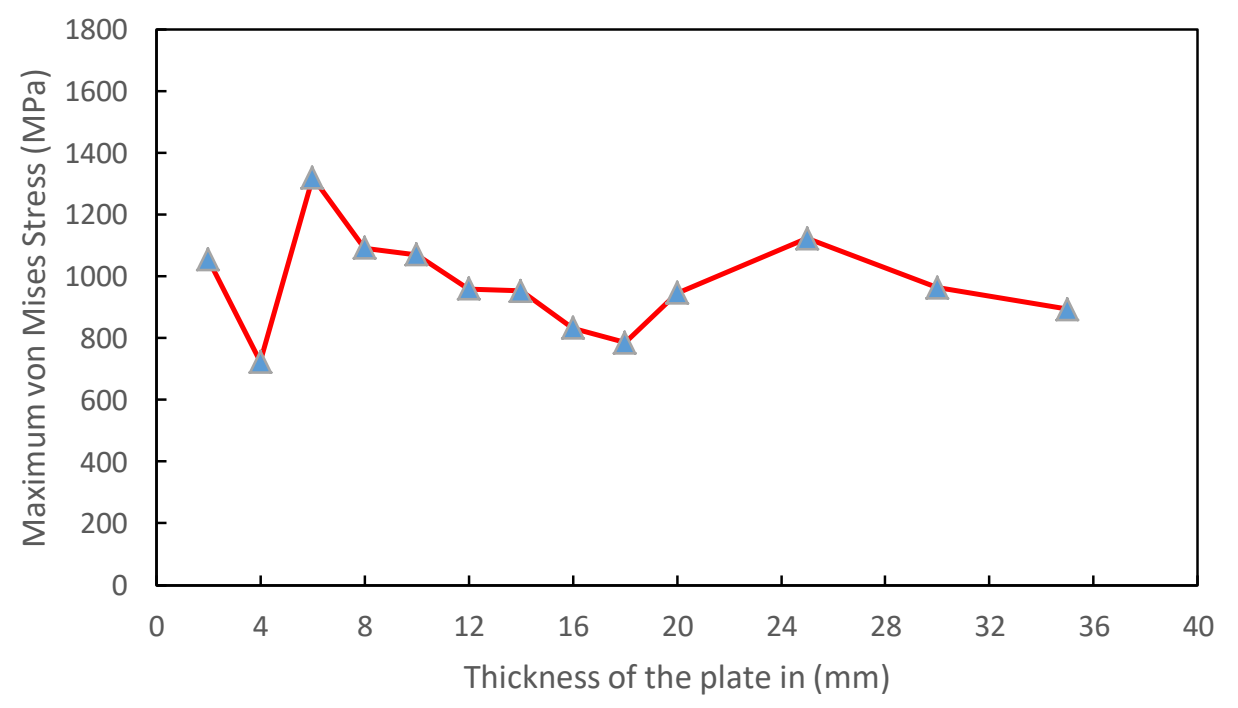

Fig. (7): The variation of maximum von Mises stress versus the thickness of the plate. 
3.2 Relationship between stress intensity factor $K$ and the thickness of the plate

Figure 8 explains the relationship between the $\mathrm{K}$ factor and the thickness of the plate. It is clear that the stress intensity factor increases when the plate thickness increased, the intensity of the equivalent stresses accumulates more significantly as the plate thickness increased.

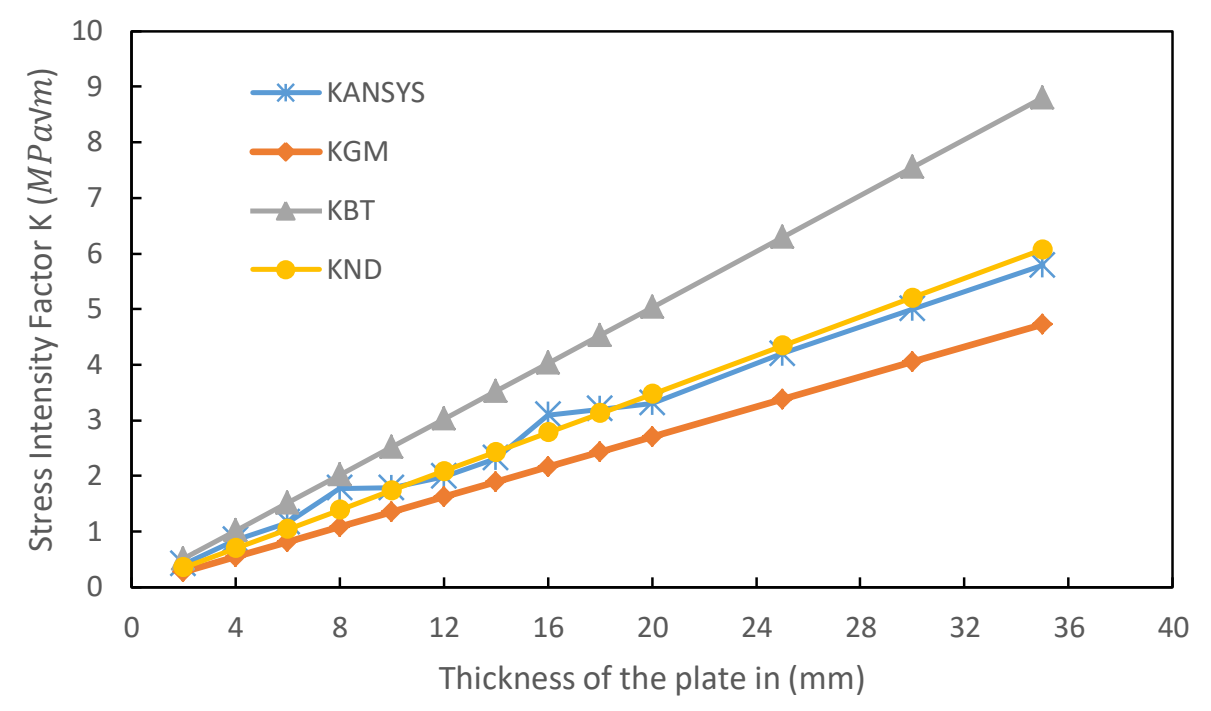

Fig. (8): Stress intensity factor $K$ versus the thickness of the plate

If the numerical results obtained from ANSYS software compared with analytical results using Equations 2, 3, and 8, (Murakami, 1987, Guo, 1999, Berezhnitskii, 1967, Tada et al., 2000, Newman Jr, 1983) as indicated in Equations 2:11 which are nominated with $K G M, K B T$, and $K N D$ where the results are shown in Figure 8. There is a good agreement between the numerical ANSYS results with the $K N D$ and also using the other equations that gives the same promotional relationship as numerical, but with different error percentages. Noticed that the thickness of the plate has a significant effect on the stress intensity distribution over the whole plate which varies proportionally according to the thickness. The stress intensity at or near the crack location will increase significantly with increasing the thickness of the plate. See Figure 6.

3.3 Error percentage between analytical results and numerical ANSYS results

The error percentage between the analytical and numerical ANSYS software results is presented in Table 2 and calculated using the following equation.

$e=\frac{K_{I}^{\text {ANSYS }}-K_{I}^{\text {Anlytical }}}{K K_{I}^{\text {Analytical }}} \times 100$ 
3.4 Table (2): Error percentage between analytical results and numerical ANSYS results

\begin{tabular}{|c|c|c|c|}
\hline Plate Thickness (mm) & Error \% (KGM) & Error \% $(K B T)$ & Error \% $(K N D)$ \\
\hline 2 & 30.43628 & 16.6416 & 18.39341 \\
\hline 4 & 33.9355 & 19.77075 & 21.56955 \\
\hline 6 & 23.04411 & 10.03121 & 11.68374 \\
\hline 8 & 40.57988 & 25.71243 & 27.60048 \\
\hline 10 & 13.32124 & 1.336614 & 2.858564 \\
\hline 12 & 4.987055 & 6.116166 & 4.706148 \\
\hline 14 & 4.962862 & 6.137801 & 4.728107 \\
\hline 16 & 22.8774 & 9.882135 & 11.53243 \\
\hline 18 & 12.75251 & 0.828026 & 2.342337 \\
\hline 20 & 4.836756 & 6.25057 & 4.84257 \\
\hline 25 & 6.635264 & 4.642269 & 3.210114 \\
\hline 30 & 5.876148 & 5.321102 & 3.899143 \\
\hline 35 & 4.92748 & 6.169441 & 4.760223 \\
\hline
\end{tabular}

The error percentage between mathematical equations are varies, for different plate thicknesses. The range of plate thickness that used in this work is large so it will be difficult to modify or add parameters to the three mathematical equations while for each thickness there is a good agreement between the numerical and mathematical results for different thicknesses, but not for all studied thicknesses in another manor each mathematical equation can be used for some ranges of plate thicknesses while for some other thickness there is a large error percentage and the other mathematical equation can be used.

\section{CONCLUSION}

This study presents the prediction of macroscopic behavior through simulating the crack in a steel plate and recording the resulted equivalent to Von Mises stresses and the stress intensity factors at different plate thicknesses. The thickness of the plate has affected the stress intensity factor where increasing the plate thickness resulted in increasing the SIF at the location of the crack. Also, the thickness of the plate has significant effect on the stress distribution over the whole plate.

\section{REFERENCES}

ALBEDAH, A., BENYAHIA, F., DINAR, H. \& BOUIADJRA, B. B. 2013. Analytical formulation of the stress intensity factor for crack emanating from central holes and repaired with bonded composite patch in aircraft structures. Composites Part B: Engineering, 45, 852-857.

BEREZHNITSKII, L. 1967. Propagation of cracks terminating at the edge of a curvilinear hole in a plate. Soviet materials science: a transl. of Fiziko-khimicheskaya mekhanika materialov/Academy of Sciences of the 
Ukrainian SSR, 2, 16-23.

BROEK, D. 2012. Elementary engineering fracture mechanics, Springer Science \& Business Media.

CAMAS, D., GARCIA-MANRIQUE, J., ANTUNES, F. \& GONZALEZ-HERRERA, A. 2020. Three-dimensional fatigue crack closure numerical modelling: crack growth scheme. Theoretical and Applied Fracture Mechanics, 102623.

CAMAS, D., GARCIA-MANRIQUE, J. \& GONZALEZ-HERRERA, A. 2011. Numerical study of the thickness transition in bi-dimensional specimen cracks. International Journal of Fatigue, 33, 921-928.

CHELL, G. \& VITEK, V. 1979. Post yield solutions for fracture mechanics analyses of cracks emanating from elliptic holes. Engineering Fracture Mechanics, 11, 251-259.

CHEONG, S. \& HONG, C. 1988. Analysis of cracks emanating from a circular hole in an orthotropic plate under mixed mode deformation. Engineering fracture mechanics, 31, 237-248.

EVANS, R., CLARKE, A., HELLER, M. \& STEWART, R. 2014. Improved stress intensity factors for a single corner crack at a loaded fastener hole. Engineering Fracture Mechanics, 131, 570-586.

FELGER, J., STEIN, N. \& BECKER, W. 2017. Asymptotic finite fracture mechanics solution for crack onset at elliptical holes in composite plates of finite-width. Engineering Fracture Mechanics, 182, 621-634.

FOLIAS, E. \& WANG, J.-J. 1990. On the three-dimensional stress field around a circular hole in a plate of arbitrary thickness. Computational Mechanics, 6, 379-391.

GARCIA-MANRIQUE, J., CAMAS, D., LOPEZ-CRESPO, P. \& GONZALEZ-HERRERA, A. 2013. Stress intensity factor analysis of through thickness effects. International Journal of Fatigue, 46, 58-66.

GUO, W. 1999. Three-dimensional analyses of plastic constraint for through-thickness cracked bodies. Engineering Fracture Mechanics, 62, 383-407.

GUO, W., ZHU, J. \& GUO, W. 2020. Equivalent thickness-based three dimensional stress fields and fatigue growth of part-through cracks emanating from a circular hole. Engineering Fracture Mechanics, 228, 106927.

HAJIMOHAMADI, M. \& GHAJAR, R. 2019. Stress intensity factors for cracks emanating from a circular hole in an infinite quasi-orthotropic plane. Fatigue \& Fracture of Engineering Materials \& Structures, 42, 743-751.

HAN, Q., WANG, Y., YIN, Y. \& WANG, D. 2015. Determination of stress intensity factor for mode I fatigue crack based on finite element analysis. Engineering Fracture Mechanics, 138, 118-126.

HELLO, G., TAHAR, M. B. \& ROELANDT, J.-M. 2012.
Analytical determination of coefficients in crack-tip stress expansions for a finite crack in an infinite plane medium. International Journal of Solids and Structures, 49, 556-566.

ISIDA, M. 1966. Stress-intensity factors for the tension of an eccentrically cracked strip.

JING, Z. \& WU, X. 2015. Wide-range weight functions and stress intensity factors for arbitrarily shaped crack geometries using complex Taylor series expansion method. Engineering Fracture Mechanics, 138, 215-232.

KHDIR, Y.-K., KANIT, T., ZAÏRI, F. \& NAÏT-ABDELAZIZ, M. 2013. Computational homogenization of elasticplastic composites. International journal of solids and structures, 50, 2829-2835.

KHDIR, Y.-K., KANIT, T., ZAÏRI, F. \& NAÏT-ABDELAZIZ, M. 2014. Computational homogenization of plastic porous media with two populations of voids. Materials Science and Engineering: A, 597, 324-330.

KHDIR, Y.-K., KANIT, T., ZAÏRI, F. \& NAÏT-ABDELAZIZ, M. 2015. A computational homogenization of random porous media: Effect of void shape and void content on the overall yield surface. European Journal of Mechanics-A/Solids, 49, 137-145.

KHDIR, Y. K. 2019. Analytical and Numerical Investigation of Hardening Behavior of Porous Media. Polytechnic Journal, 9, 1-10.

LAM, K., TAY, T. \& WANG, W. 1996. The Dugdale solution for cracks at the edge of an elliptical hole in an infinite and finite plate. Engineering fracture mechanics, 53, 97-106.

LEPORE, M., CARLONE, P., BERTO, F. \& SONNE, M. R. 2017. A FEM based methodology to simulate multiple crack propagation in friction stir welds. Engineering Fracture Mechanics, 184, 154-167.

LI, B., KOYAMA, M., HAMADA, S. \& NOGUCHI, H. 2019. Effect analysis of stress-intensity-factor-range decreasing rate for obtaining threshold stress-intensity-factor-range. Theoretical and Applied Fracture Mechanics, 104, 102377.

LIU, R., CHEN, T., LI, L. \& TATEISHI, K. 2019. A practical stress intensity factor formula for CFRP-repaired steel plates with a central crack. Journal of Constructional Steel Research, 162, 105755.

LIU, S. \& DUAN, S. 2014a. Analytical solutions of cracks emanating from an elliptic hole in an infinite plate under tension. Chinese Journal of Mechanical Engineering, 27, 1057-1063.

LIU, S. \& DUAN, S. 2014b. Analytical solutions of cracks emanating from an elliptical hole under shear. Chinese Journal of Aeronautics, 27, 829-834.

MURAKAMI, Y. 1987. Stress intensity factors. 
NEWMAN, J. 1981. A crack-closure model for predicting fatigue crack growth under aircraft spectrum loading. Methods and models for predicting fatigue crack growth under random loading. ASTM International.

NEWMAN JR, J. 1983. A nonlinear fracture mechanics approach to the growth of small cracks. NATIONAL AERONAUTICS AND SPACE ADMINISTRATION HAMPTON VA LANGLEY RESEARCH CENTER.

NEWMAN JR, J. \& DANIEWICZ, S. 2014. Predicting crack growth in specimens with overloads and cold-worked holes with residual stresses. Engineering Fracture Mechanics, 127, 252-266.

NUI, L., CHEHIMI, C. \& PLUVINAGE, G. 1994. Stress field near a large blunted tip $V$-notch and application of the concept of the critical notch stress intensity factor (NSIF) to the fracture toughness of very brittle materials. Engineering Fracture Mechanics, 49, 325-335.

PENG, D., WALLBRINK, C. \& JONES, R. 2005. Stress intensity factor solutions for finite body with quarter-elliptical flaws emanating from a notch. Engineering fracture mechanics, 72, 1329-1343.

PILKEY, W. D. \& PILKEY, W. D. 1994. Formulas for stress, strain, and structural matrices, Wiley New York.

ŞAHIN, H. \& AYHAN, A. O. 2019. Three-Dimensional Mixed Mode Stress Intensity Factors for Inclined Elliptical Surface Cracks in Plates under Uniform Tensile Load. Procedia Structural Integrity, 21, 38-45.

SCHIJVE, J. 2001. Fatigue of structures and materials, Springer Science \& Business Media.

SHARMA, D. S. \& UKADGAONKER, V. G. Stress Intensity Factors for Cracks Emanating from a Circular Hole in Laminated Composite Infinite Plate Under Different Loading Conditions. 2008 First International Conference on Emerging Trends in Engineering and Technology, 2008. IEEE, 781-786.

SHIVAKUMAR, V. \& FORMAN, R. 1980. Green's function for a crack emanating from a circular hole in an infinite sheet. International Journal of Fracture, 16, 305-316.

SOUIYAH, M., ALSHOAIBI, A., MUCHTAR, A. \& ARIFFIN, A. 2008. Stress intensity factor evaluation for crack emanating from circular-hole using finite element method. International review of mechanical engineering, 2.

STAWIARSKI, A. 2018. The nondestructive evaluation of the GFRP composite plate with an elliptical hole under fatigue loading conditions. Mechanical Systems and Signal Processing, 112, 31-43.

TADA, H., PARIS, P. \& IRWIN, G. 2000. The analysis of cracks handbook. New York: ASME Press, 2, 1.

VISHNUVARDHAN, S. 2020. Effect of constraints on stress intensity factor for dissimilar metal plate with centre crack under uniform tension. Materials Today Communications, 22, 100807.

WEIBGRAEBER, P., FELGER, J., GEIPEL, D. \& BECKER, W. 2016. Cracks at elliptical holes: stress intensity factor and finite fracture mechanics solution. European Journal of Mechanics-A/Solids, 55, 192-198.

WU, X., ZHAO, X., XU, W. \& TONG, D. 2018. Discussions on weight functions and stress intensity factors for radial crack (s) emanating from a circular hole in an infinite plate. Engineering Fracture Mechanics, 192, 192-204.

YAN, X. 2006. A numerical analysis of cracks emanating from an elliptical hole in a 2-D elasticity plate. European Journal of Mechanics-A/Solids, 25, 142-153.

YAN, X. 2007. Rectangular tensile sheet with single edge crack or edge half-circular-hole crack. Engineering Failure Analysis, 14, 1406-1410.

YANG, J., ZHOU, Y.-T., MA, H.-L., DING, S.-H. \& LI, X. 2017. The fracture behavior of two asymmetrical limited permeable cracks emanating from an elliptical hole in one-dimensional hexagonal quasicrystals with piezoelectric effect. International Journal of Solids and Structures, 108, 175-185. 